\title{
A Decisão Eficaz
}

Autor: PETER DRUCKER

Tradução de OLGA FERRINI DE FARIA

Fonte: "Harvard Business Review (Jan/Feb. 1967)

... resulta de um processo sistemático, com elementos claramente definidos, que é dirigido numa seqüência distinta de passos.

Os bons executivos não tomam um grande número de decisões: concentram-se no que é importante. Tentam tomar as poucas decisões importantes, no seu mais alto nivel conceitual. Procuram as constantes de uma situação, para examinar o que é estratégico e genérico, e não apenas "resolver problemas". Não estão, portanto, grandemente impressionados com a velocidade da tomada de decisão; consideram, até, a excessiva habilidade para manipular um grande número de variáveis um sintoma de julgamento menos consciente. $O$ que lhes interessa é saber a respeito de que trata a decisão e quais as realidades magnas que ela deve satisfazer. Estão mais preocupados com o impacto que com a técnica, mais com o bom senso que com habilidade.

Sabem quando uma decisão deve ser baseada em principios e quando deve ser tomada pragmaticamente, de acordo com os aspectos do caso.
A decisão mais dificil está entre a opção acertada e a opção desacertada, sabem como distinguir entre as duas. O passo mais demorado no processo decisório não é tomar a decisão, mas colocá-la em execução. A menos que ela tenha "degenerado em trabalho", não terá sido uma decisão, mas, no máximo, uma declaração de intenção. Isto significa que, enquanto a decisão propriamente dita baseia-se no mais alto nivel de compreensão conceitual o cometimento da ação deve estar tão próximo quanto possivel da capacidade daqueles que vão executá-la.

Acima de tudo, um bom executivo sabe que o processo decisório tem sua sistemática e seus elementos claramente definidos.

\section{Seqüência de passos}

Os elementos, por si sós, não levam à decisão. Na verdade, cada decisăo é um julgamento arriscado. Mas, a menos que esses elementos sejam os pontos de apoio do processo decisório, o executivo não chegará a uma decisão acertada e muito menos a 
uma decișăo eficaz. Neste artigo, portanto, procuraremos descrever a seqüência de passos do processo decisório. Os passos são seis:

1 - A classificação do problema. É genérico? É excepcional e único? Ou é a primeira manifestação de uma nova modalidade para a qual uma norma deverá ser formulada?

2 - A definição do problema. Qual a matéria com que vamos lidar?

3 - As especificações a que a solução do problema deve atender. Quais são as condições-limite?

4 - A decisão sobre o que é "acertada", mais do que "aceitável", a fim de encontrar as condições-limite. 0 que satisfará plenamente as especificações, antes que se dê atenção aos compromissos, adaptações e concessões que tornem aceitável a decisão?

5 - A formulação do esquema de ação a ser desenvolvido. Que ação deverá ser cometida? Quem deverá saber a respeito?

6 - A realimentação, que testa a validade e a eficácia da decisão contra o curso natural dos acontecimentos. Como está sendo executada a decisão? As premissas em que foi baseada săo corretas ou obsoletas?

Vejamos cada um desses elementos de per si.

Nota do Autor: Este artigo é extraído de um capitulo do meu próximo livro "The Effective Executive", a ser publicado por Harper \& Row, Publishers, Inc.

\section{A classificação}

O executivo pergunta-se: Trata-se de um sintoma de desordem fundamental, ou de um fato isolado? O fato genérico sempre pode ser tratado com uma norma, um princípio. Mas o fato excepcional só pode ser tratado como tal e quando se manifesta.

Estritamente falando, o executivo poderia distinguir entre quatro mais facilmente que entre dois tipos diferentes de ocorrência.

Primeiramente, há o fato verdadeiramente genérico, de que o evento singular é apenas um sintoma. Muitos dos "problemas" que se apresentam no curso do trabalho de um executivo são desta ordem. Decisões imaginosas em negócios não são "decisões". São adaptações. O problema é genérico. Isto é ainda mais freqüente em organizações manufatureiras. Por exemplo:

A equipe de controle e engenharia de produção certamente lidará com centenas de problemas no curso de um mês. Entretanto, sempre que esses problemas são analisados, em grande maioria, provam-se apenas sintomas e manifestações - de situações básicas subjacentes. $O$ engenheiro de controle ou o engenheiro de produção que trabalha num compartimento estanque não pode ver isto. Ele pode tér algumas dificuldades com as juntas das tubulações de vapor, e é só.

Somente quando se analisar a carga total de trabalho de uma equipe em vários meses é que o problema gené- 
rico se apresentará como tal. Então se verificará que a temperatura e a pressão tornaram-se elevadas demais para os equipamentos, e que as juntas devem ser redesenhadas, para poderem suportar cargas maiores. Até que essa análise seja feita, a equipe gastará muito tempo vedando escapamentos, sem conseguir controlar a situação.

O segundo tipo de ocorrência é o problema que, embora se apresente como fato isolado na organização, é, na verdade, genérico. Consideremos:

A companhia que recebe uma oferta para fundir-se com outra, Jamais receberá tal oferta outra vez, se a aceitar. É uma situação irreversível, para a organização individual sua diretoria e sua gerência. Mas é, naturalmente, uma situação comum, que se apresenta inúmeras vezes. Decidir sobre a aceitação ou não de uma tal oferta exige a observância de certas normas. Para estas, entretanto, o executivo terá de valer-se da experiência de terceiros.

A seguir, temos o evento verdadeiramente excepcional, que 0 executivo deve identificar. llustrando: A falta de energia que mergulhou na escuridão as regiões norte e nordeste dos EUA, desde St. Lawrence a Washington em novembro de 1965 era, segundo as primeiras notícias, uma situação realmente excepcional. Assim também a tragédia da talidomida, que causou o nascimento de tantas crianças deformadas nos principios da década de 60. As probabilidades de verificação de qualquer destes eventos eram de um para dez milhões, ou de um para cem milhões e a simultaneidade entre eles era de repetição tão improvável quanto seria, por exemplo, a desintegração em seus átomos da cadeira em que o leitor se acha sentado.

Os fatos verdadeiramente únicos são raros. Quando o evento se manifesta, - executivo deve indagar se se trata realmente de uma exceção, ou se é apenas a primeira manifestação de um novo tipo de fato. $E$ isto - a manifestação primeira de um novo problema genérico - é a quarta e última categoria de fatos com que lida o processo decisório. Assim, sabemos hoje que tanto o colapso de energia no nordeste dos EUA como a tragédia da talidomida eram apenas as primeiras manifestações de situações que, sob condições da tecnologia e da farmacologia modernas, poderão tornar-se bastante freqüentes, a não ser que soluções genéricas sejam encontradas.

Todos os fatos, à exceção dos realmente únicos, requerem soluções gerais. Eles requerem uma norma, um princípio, uma politica. Uma vez que o princípio correto tenha sido aplicado, todas as demais manifestações da situação podem ser tratadas pragmaticamente, isto é, por adaptação da regra às circunstâncias concretas do caso. Os fatos isolados devem ser tratados individualmente. $O$ executivo não pode desenvolver normas para $\circ$ que é excepcional.

O executivo eficaz aplica-se a identificar com qual das situações acima está tratando, e sabe que decidirá erradamente se classificá-la de modo incorreto. 
O mais comum dos enganos cometidos no processo decisório é o tratar uma situação genérica como se fora uma série de fatos isolados, isto é, ser pragmático por falta de compreensão da situação, e de princípios para controlá-la. O resultado inevitável é frustração. Isto foi claramente demonstrado em muitos itens da política interna e externa da Administração Kennedy.

A despeito do brilhantismo de seus membros, a Administração obteve apenas um sucesso fundamental, e este foi na crise dos misseis cubanos. No mais, conseguiu praticamente nada. A razão principal foi, certamente, o que seus membros chamavam "pragmatismo", isto é, a recusa da Administração à formulação e ao desenvolvimento de normas e princípios, e sua insistência em tratar cada coisa "de acordo com seus méritos". Entretanto, estava patente para todos, inclusive os membros da Administração, que as premissas básicas em que se apoiava a sua política - as premissas válidas para os anos imediatos ao pós-guerra - haviam-se tornado irrealisticas nos anos 60 , tanto nos assuntos internos quanto nos internacionais.

Igualmente comum é o erro de tratar um novo evento como se fora apenas mais um exemplo de um problema antigo, ao qual se aplicariam normas já existentes.

Este foi o erro que deixou agravarse o deficit local de energia na fronteira New-York/Ontario até que ele se tornasse o maior colapso de toda a região nordeste. Os engenheiros especialistas, notadamente na Cidade de
New York aplicaram as normas correspondentes a uma situação de sobrecarga rotineira. Entretanto, seus instrumentos haviam denunciado uma situação extraordinária, que estava a exigir medidas excepcionais de controle.

Ao contrário, a única grande vitória do Presidente Kennedy na crise dos misseis cubanos resultou de sua aceitação do desafio de uma questão excepcional e extraordinária. Tão logo ele aceitou esse desafio, seus inegáveis recursos de inteligência e coragem entraram em cena.

\section{A definição}

Uma vez que o problema foi classificado como geral ou excepcional fica razoavelmente fácil definí-lo. "De que se trata". O que é pertinente aqui? Qual a chave para esta situação?" Estas perguntas são conhecidas. Mas só os executivos competentes estão atentos para o perigo deste passo, que não é a definição errada, mas a definição plausivel, porém incompleta.

Assim, a indústria automobilística americana ateve-se a uma definição plausivel, mas incompleta, do problema da segurança. Foi esta falha mais que a relutância em investir na engenharia de segurança - que, em 1966, acabou por colocar a indústria sob os ataques do Congresso pela falta de segurança de seus carros, deixando-a preocupada. Simplesmente, não é verdade que a indústria automobilística tenha relegado a questão da segurança.

Pelo contrário, trabalhou por mais segurança na engenharia de trânsito 
e no treinamento de motoristas, julgando que essas seriam as áreas prioritárias. Que os acidentes são causados por estradas e motoristas inseguros é aceito como plausível. De fato, todos os órgãos envolvidos de alguma forma com a segurança de trânsito, desde a polícia rodoviária às escolas, fizeram campanhas nesse sentido. Campanhas que tiveram algum resultado. $O$ número de acidentes em estradas decaiu bastante, e, da mesma forma, motoristas que haviam recebido treinamento de segurança foram envolvidos em menor número de acidentes.

Mas, apesar de 0 índice de acidentes em cada 1.000 carros, ou em cada 1.000 milhas percorridas ter caído, o número total de acidentes e o seu grau de seriedade continuaram em ascensão. Deveria ter ficado claro desde o princípio que algo deveria ser feito a respeito da pequena mas importante probabilidade de que os acidentes ocorressem a despeito das leis e do treinamento de segurança.

Isto significa que as futuras campanhas de segurança deverão ser acompanhadas de medidas que tornem os acidentes menos perigosos. Apesar de os carros terem sido projetados para serem seguros quando dirigidos. corretamente, deverão ser projetaḍos também para oferecer segurança mesmo quando usados incorretamente.

Só há uma garantia contra o risco de sermos presa de uma definição incompleta do problema: testá-la várias vezes, contra todos os fatos observáveis e abandoná-la tão logo ela dei$x e$ de ajustar-se a qualquer deles.
O bom executivo sempre testa os indícios de que algo atípico ou extraordinário esteja ocorrendo. Ele interroga se a sua definição explica os fatos observados, e se explica-os todos. Ele anota $\circ$ que a definição deve produzir em termos de acontecimentos, por exemplo, fazer desaparecer os acidentes de carro - e então testa regularmente, a fim de verificar se isto realmente ocorre. Finalmente, ele volta a examinar toda a questão sempre que verifica algo atípico, quando se defronta com fenômenos que sua definição não explica, ou quando o curso dos acontecimentos se desvia, mesmo por detalhes, de sua previsão.

Estas são em essência as regras que Hipócrates estabeleceu para o diagnóstico médico há mais de 2000 anos. São as regras da observação cientifica primeiramente formuladas por Aristóteles e reafirmadas por Galileu há 300 anos. São, em outras palavras, regras bem conhecidas e testadas, que um executivo pode aprender a aplicar sistematicamente.

\section{As especificações}

O outro elemento importante do processo decisório é a definição clara do que a decisão deve acarretar. Quais os objetivos que deve alcançar? Quais os indices mínimos a atingir? Em ciência estas são as condições-limite. Uma decisão, para ser eficaz, deve atingir essas condições-limite. Consideremos: Alfred P. Sloan, ao assumir a direção da General Motors em 1922, provavelmente perguntou-se se as necessidades da empresa seriam satisfeitas com a retirada da au- 
tonomia dos diretores de divisão. Sua resposta foi claramente negativa. As condiçōes-limite de seu problema demandavam autoridade e responsabilidade nas posições de chefia de operações. Isto era tão necessário quanto - controle e a unidade na cúpula. Todos antes de Sloan haviam visto a questão como de personalidades - a ser resolvida através de uma luta pelo poder da qual um homem saisse vitorioso. As condições-limite, Sloan verificou, demandavam solução para um problema institucional - a ser resolvido através de uma nova estrutura: descentralização, para equilibrar a autonomia local de operações com controle central de direção e política.

A decisão que não satisfaz às condições-limite é pior que a definição errada do problema... E completamente impossivel salvar uma decisão que parte de premissas certas mas desvia-se antes de chegar às conclusões certas. Além do mais, é preciso ter uma idéia clara das condições-limite para saber-se quando uma decisão deve ser abandonada. A causa mais comum do fracasso de uma decisão não reside no fato de ela ter sido errada de inicio. Na maioria das vezes, a mudança subseqüente de objetivos as especificações - é o que torna uma decisão anteriomente acertada repentinamente insatisfatória. $E$, a menos que o executivo tenha mantido claramente definidas as condições-limite, para possibilitar a imediata reforma de uma decisão já em andamento através da adoção de nova política mais apropriada, ele poderá até não perceber que as coisas mudaram. Por exemplo:
Franklin D. Roosevelt foi severamente criticado por sua mudança de candidato conservador em 1932 para Presidente radical em 1933. Mas não era Roosevelt que havia mudado. O repentino colapso econômico que se verificou entre o verão de 1932 e a primavera de 1933 mudara as especificações. A política apropriada para 0 objetivo de recuperação econômica nacional - que poderia ter, sido uma política econômica conservadora deixou de ser a acertada quando, com o "Bank Holiday", o objetivo teve de passar a ser a coesão política e social. Quando as condiçőes-limite mudaram, Roosevelt imediatamente substituiu o objetivo politico (reforma) pelo seu objetivo econômico anterior (recuperação).

A definição clara sobre as condições-limite é necessária, acima de tudo, para a identificação da mais dificil das decisões: aquela em que as especificaçőes a serem satisfeitas são essencialmente incompativeis. Em outras palavras esta é a decisão que poderia - poderia, apenas - ser eficaz se nada mais corresse mal. Um caso clássico foi a decisão do Presidente Kennedy sobre a Baía dos Porcos:

Uma especificação, é claro, estava em derrotar Castro. A outra era fazer parecer que a invasão fora um levante "espontâneo" dos cubanos. Mas estas duas especificações só seriam compatibilizadas se um levante imediato contra Castro varresse toda a ilha, paralisando completamente o exército cubano. E conquanto isto não fosse impossivel năo era tampouco provável, num Estado tão ferreamente controlado. 
Uma decisão como esta é comumente chamada "jogo". Mas na verdade elas derivam de algo menos racional que uma jogada, isto é, da esperança, contra toda possibilidade de que duas especificações claramente incompativeis possam ser satisfeitas simultaneamente. Isto é, esperar por um milagre, e a questão com os milagres não é que sejam tão raros, mas que sua verificação seja de todo imprevisivel.

Todos podem errar. Na verdade, todos nós, às vezes, tomamos decisões erradas. Mas nenhum executivo precisa tomar uma decisão que em si mesma pareça ter eficácia, porém, na realidade falhe na satisfação das condições-limite.

\section{A decisão}

O executivo deve partir do que é "correto", preferencialmente ao do que é "aceitável", precisamente porque ele sempre tem de fazer concessöes no final. Mas se ele não sabe o que satisfará as condições-limite, não poderá distinguir entre a concessão acertada e a desacertada.

Consideremos: Aprendi isto quando comecei em 1944 meu primeiro grande contrato de consultoria. Era um estudo da estrutura de direção e política da General Motors. Alfred P. Sloan Jr., que era o Presidente e principal executivo da Cia., chamou-me ao seu escritório e disse-me: "Não Ihe direi o que estudar, o que relatar ou a que conclusões chegar. Isto é sua tarefa. Minha única instrução é que você relate o que você achar que é certo. Não se preocupe com a nossa reação. Não se preocupe se vamos gostar disto ou se vamos gostar daquilo. $E$, acima de tudo, não se envolva com concessões que possam tornar suas conclusões inaceitáveis. Não há um só executivo nesta Cia. que năo saiba fazer todas as concessốes imagináveis sem a sua ajuda. Mas ele não poderá fazer a concessão acertada, a não ser que você lhe diga o que será acertado.

O executivo sabe que há dois diferentes tipos de concessão. Um está expresso no velho provérbio: "Meio pão é melhor que nenhum pão". o outro, na estória do Julgamento de Salomão, claramente baseado no reconhecimento do fato de que "meia criança é pior que criança nenhuma".

No primeiro caso, as condições-limite estão ainda sendo atendidas: a finalidade do pão é servir de alimento, e meio pão é ainda alimento. Numa criança, entretanto, não satisfaz as condições-limite, pois meia criança não pode viver e crescer.

É perda de tempo preocupar-se com - que será aceitável e o que o executivo deveria ou não dizer a fim de não causar resistência (as coisas com que nos preocupamos raras vezes acontecem, ao passo que objeções e dificuldades em que nem se pensaria podem de um momento para outro provar-se como obstáculos quase intransponiveis). Em outras palavras, o executivo nada ganhará em começar com a pergunta - o que é aceitável? - Pois enquanto a responde, abandona as coisas importantes e perde a chance de apresentar-se com uma resposta eficaz. 


\section{$A$ ação}

Converter a decisão em ação é o quinto elemento mais importante do processo decisório. Enquanto a avaliação das condições-limite é o passo mais difícil no processo decisório, a conversão da decisão em ação é o mais demorado. Entretanto uma decisão não se efetivará a menos que o cometimento da ação tenha feito parte dela desde o princípio. De fato, não terá havido decisão a menos que sua execução em passos específicos tenha sido cometida à responsabilidade e ao trabalho de alguém. Até então, terá sido apenas uma boa intenção.

A falha em muitas diretrizes politicas, especialmente as comerciais, é que elas não contêm o esquema de ação - a sua execução não é tarefa específica nem de responsabilidade de ninguém. Poucos se preocupam com - fato de que o pessoal da organização as veja com ironia, se não como declarações do que a alta direção realmente não vai fazer.

Converter a decisão em ação requer resposta a diversas questões: Quem deve saber a respeito desta decisão? Que ação deve ser encetada? Quem a encetará? Que ação deveria ser para que as pessoas a executá-la possam fazê-lo? A primeira e a última destas questões.são muitas vezes desconsideradas - com resultados calamitosos. Uma história que já se tornou lenda entre os pesquisadores de operações ilustra a importância da primeira questão: Um dos principais produtores de equipamento industrial decidiu, há alguns anos, interromper a fabricação de uma peça que fora durante vários anos o equipamento standard de uma linha de tornos mecânicos, muitos dos quais ainda se achavam em uso. Decidiu-se, então, vender ainda a peça aos proprietários do antigo equipamento por mais 3 anos, para reposição, e então encerrar a fabricação e a venda. As vendas dessa peça vinham caindo havia vários anos.

Mas elas paralisaram imediatamente depois que os clientes aumentaram seus pedidos em razão de estar prestes a encerrar-se a fabricação. Ninguém, entretanto, se perguntara: Quem precisa saber desta decisão?

Em conseqüência, ninguém informara ao Chefe de compras, que tinha sob sua responsabilidade a aquisição de material para o fabrico. Suas instruções eram comprá-lo numa dada quantidade para as vendas correntes - e continuarem sem alteração.

Assim quando chegou o momento de encerrar-se a fabricação, a companhia possuía em seu almoxarifado material bastante para mais 8 a 10 anos de produção, material que teve de receber baixa, com prejuizo considerável.

A ação deve estar à altura da capacidade da pessoa a que é cometida.

Uma grande companhia química americana viu-se, há poucos anos, com elevados saldos bancários bloqueados em países da África Ocidental. Para proteger esse dinheiro, a alta diretoria resolveu investi-lo localmente em negócios que 
a) pudessem contribuir para a economia local.

b) não necessitassem de importação, e

c) pudessem, se bem sucedidos, ser vendidos a investidores locais, se e quando as remessas de lucros fossem novamente possiveis.

Para estabelecer esses empreendimentos, a Cia. desenvolveu um processo simples de preservação de uma fruta tropical - um dos principais produtos de ambos os países - que, até então, vinha sofrendo sérios danos no transporte para seus mercados ócidentais.

O empreendimento foi um sucesso em ambos os paises. Mas num deles o diretor local estabeleceu-o de tal modo que requeria gerência altamente qualificada e tecnicamente treinada, de um tipo dificil de obter-se na África Ocidental. No outro, o diretor local ponderou a capacidade daqueles que eventualmente deveriam gerir o negócio. Em conseqüência, esforçou-se por tornar simples o processo e sua gerência e por formar seus quadros de pessoal até o nível de direção desde o princípio, com pessoal nacional.

Alguns anos mais tarde, tornou-se novamente possivel a' transferência de saldos destes dois paises. Mas, apesar de o investimento ter-se desenvolvido, não se encontrou comprador no primeiro país. Ninguém no país possuía a necessária habilitaçăo gerencial e técnica para dirigí-lo, e assim ele teve de ser liquidado com prejuizo. No outro pais, tantos investidores estavam interessados em adquiri-lo que a companhia pôde repatriar seu investimento original com um lucro significativo.

O processo comercial e o investimento eram essencialmente 0 mesmo em ambos os paises. Mas no $1 .^{\circ}$, ninguém perguntara: de que tipo de pessoas dispomos para tornar efetiva esta decisão? Que podem elas fazer? Como resultado, frustrou-se a própria decisão.

Esse cometimento da ação torna-se duplamente importante, quando as pessoas precisam alterar seu comportamento, seus hábitos ou atitudes para executar uma decisão. Aqui, o executivo deve certificar-se não só de que a responsabilidade da execução está claramente cometida, mas também de que as pessoas designadas são capazes de desempenhá-la.

Assim, o executivo deve estar certo de que a avaliação, o padrão de desempenho e a retribuição daqueles feltos responsáveis pela ação também mudaram.

De outra forma o pessoal da organização será presa de um conflito emocional interno paralisante. Consideremos os seguintes exemplos:

- Quando Theodore Vail era presidente da Bell Telephone System há 60 anos, decidiu que o negócio da Bell System era prestação de serviços. Esta decisăo explica porque nos EUA e no Canadá o sistema telefônico é ainda hoje uma empresa privada. Entretanto, essa diretriz política poderia 
ter permanecido letra morta se Vail não tivesse ao mesmo tempo estabelecido padrões de avaliação da qualidade dos serviços prestados e introduzido esses padrões como fator de avaliação e, em conseqüência, retribuição do desempenho gerencial. Os diretores da Bell daquela época estavam acostumados a ser avaliados pela rentabilidade (ou ao menos pelo custo) de suas unidades. Os novos padrões de avaliação acarretaram a rápida aceitação dos novos objetivos.

- em flagrante contraste está o recente fracasso de um brilhante presidente $e$ diretor-executivo em tornar efetivos a nova estrutura organizacional e os novos objetivos de uma antiga e importante companhia, orgulho dos EUA. Todos estavam de acordo em que era necessário mudar. A Cia., depois de muitos anos de liderança industrial, mostrava sinais definitivos de esclerosamento. Estava sendo batida em muitos mercados, pelos competidores mais novos, menores, porém mais agressivos. Mas, contrariamente ao requerido para conseguir a aceitação das novas idéias, o presidente para aplacar a oposição - promoveu representantes da velha escola aos mais altos e melhor remunerados postos - particularmente a três novas vice-presidências. Isto significou apenas uma coisa para o pessoal da companhia: "eles não estão realmente interessados". Se as maiores recompensas são dadas a comportamentos contrários àquele requerido pelo novo curso da açăo, todos concluem que aquele comportamento é, realmente, o desejado e a ser recompensado pela alta direção.
Só os mais eficientes executivos podem conseguir o que Vail conseguiu - alicerçar a execução da decisão dentro dela mesma. Mas qualquer executivo pode examinar os cometimentos de ação exigidos por uma decisão, que atribuições de execução se seguem dela e que pessoas estão em condições de exercê-las.

\section{A realimentação}

Finalmente um sistema de informações deve ser estabelecido como parte da decisão, para propiciar teste contínuo dos objetivos da decisão contra fatos eventuais. As decisões são tomadas por pessoas e pessoas săo falíveis, e seu trabalho não dura muito. Mesmo a melhor decisão tem uma alta probabilidade de estar errada. Mesmo a mais acertada pode eventualmente tornar-se obsoleta.

Isto certamente não precisa ser documentado. E certamente qualquer executivo estabelece uma realimentação - relafórios, dados estatísticos, estudos - na sua decisăo, para referência e reorientação.

Entretanto inúmeras decisões falham na obtenção dos resultados esperados, ou, até, na sua própria efetivação, a despeito de todo o sistema de realimentação. Assim como não se pode ter a visão do Monte Matterhorn apenas examinando o mapa da Suiça (uma abstração), uma decisão não pode ser acuradamente avaliada pelo estudo de um relatório. $\mathrm{E}$ isto porque relatórios são abstrações. 
Os executivos sabem disto e seguem uma regra que os militares desenvolveram há muito. O comandante que toma uma decisão não fica na dependência de relatórios para verificar se está sendo cumprida. Ele - um de seus oficiais - vai observar. A razão não é que os bons executivos ou os bons comandantes desconfiem de seus subordinados. A razão é que eles aprenderam a desconfiar de comunicações abstratas.

Com o aparecimento dos computadores, este elemento de realimentação tornar-se-á ainda mais importante, pois o executivo será muito provavelmente afastado ainda mais do campo de ação propriamente dito. A não ser que ele se convença de que o melhor a fazer é ir observar o campo de ação, estará cada vez mais divorciado da realidade. Tudo que um computador pode manejar são abstrações. E abstrações só merecem fé se forem constantemente conferidas com os resultados concretos. De outra maneira elas certamente levarão a enganos.

Observar pessoalmente. é também a melhor senão a única maneira de um executivo testar se as premissas em que baseou sua decisão são ainda válidas ou se estão se tornando obsoletas e precisam ser reexaminadas. $E$ o executivo deve sempre estar preparado para o fato de que suas premissas se tornem obsoletas mais cedo ou mais tarde. A realidade não permanece a mesma muito tempo.

Deixar de fazer observação pessoal e a razão típica de persistir numa orientação depois que ela deixou de ser adequada ou até racional.

Isto é verdadeiro tanto nas questōes de negócios como nas questões de politica governamental. Explica em grande parte o fracasso da política de Stalin na guerra fria européia, mas também a inabilidade dos Estados Unidos para ajustar sua política à realidade de uma Europa restaurada para a prosperidade e o crescimento econômico, e - fracasso da Inglaterra na aceitação, ainda que tardia, do Mercado Comum Europeu. Além disso, deixar de verificar pessoalmente a clientela, e os mercados, os competidores e seus produtos, é também, em qualquer negócio, a razão principal de decisões ineficazes e erradas.

O executivo necessita de informaçōes sistemáticas para realimentação. Ele necessita de relatórios e dados. Mas, a menos que ele baseie sua realimentação na observação direta da realidade - a menos que ele se disponha a observar pessoalmente - ele se condenará a um dogmatismo estéril.

\section{Conclusão}

Tomar decisões é apenas uma das tarefas de um executivo, em que ele emprega uma pequena parte do seu tempo. Mas tomar as decisões importantes é tarefa especificamente de executivo. Só um executivo pode tomar tais decisōes.

Um executivo eficaz toma essas decisões através de um processo sistemático, com elementos claramente definidos e numa sequeencia de passos distinta. 
Na realidade, é do executivo eficaz que se esperam, em virtude de sua posição ou do seu conhecimento, as decisões importantes, de impacto positivo em toda a organização, seu funcionamento e seus resultados.

"A causa do relâmpago", - disse Alice com muita segurança, pois ti- nha certeza disso - "é o trovão ... não, não . .. eu queria dizer o contrário".

"É tarde para corrigir", disse a Rainha. "Quando V. diz uma coisa, ela fica dita, e V. deve sofrer as conseqüências".

Lewis Carroll - "Through the Looking Glass" 